\title{
Biofilm formation on titanium implants counteracted by grafting gallium and silver ions
}

\author{
Andrea Cochis, ${ }^{1,2}$ Barbara Azzimonti, ${ }^{1,2}$ Cinzia Della Valle, ${ }^{2,3}$ Roberto Chiesa, ${ }^{2,3}$ \\ Carla Renata Arciola, ${ }^{4,5}$ Lia Rimondini ${ }^{1,2}$ \\ ${ }^{1}$ Department of Health Sciences, University of Piemonte Orientale "A. Avogadro", Novara, Italy \\ ${ }^{2}$ National Interuniversity Consortium for Materials Science and Technology (INSTM), Florence, Italy \\ ${ }^{3}$ Department of Chemistry, Materials Sciences and Chemical Engineering, Politecnico di Milano, Milan, Italy \\ ${ }^{4}$ Research Unit on Implant Infections, Rizzoli Orthopedic Institute, Bologna, Italy \\ ${ }^{5}$ Department of Experimental, Diagnostic and Specialty Medicine (DIMES), University of Bologna, Bologna, Italy
}

Received 22 February 2014; revised 15 June 2014; accepted 30 June 2014

\begin{abstract}
Biofilm-associated infections remain the leading cause of implant failure. Thanks to its established biocompatibility and biomechanical properties, titanium has become one of the most widely used materials for bone implants. Engineered surface modifications of titanium able to thwart biofilm formation while endowing a safe anchorage to eukaryotic cells are being progressively developed. Here surfaces of disks of commercial grade 2 titanium for bone implant were grafted with gallium and silver ions by anodic spark deposition. Scanning electron microscopy of the surface morphology and energy dispersive $X$-ray spectroscopy were used for characterization. Gallium-grafted titanium was evaluated in comparison with silver-grafted titanium for both in vivo and in vitro antibiofilm properties and for in vitro compatibility with human primary gingival fibroblasts.
\end{abstract}

Surface-modified materials showed: (i) homogeneous porous morphology, with pores of micrometric size; (ii) absence of cytotoxic effects; (iii) ability to support in vitro the adhesion and spreading of gingival fibroblasts; and (iv) antibiofilm properties. Although both silver and gallium exhibited in vitro strong antibacterial properties, in vivo gallium was significantly more effective than silver in reducing number and viability of biofilm bacteria colonies. Gallium-based treatments represent promising titanium antibiofilm coatings to develop new bone implantable devices for oral, maxillofacial, and orthopedic applications.

Key Words: biofilm, biomaterials, implant infections, anodic spark deposition

\section{INTRODUCTION}

Oral and orthopedic implants may be colonized by biofilmforming bacteria that cling to the prosthesis surfaces and lead to periprosthesis infections. Then bacteria, protected, as they are, by the robust covering of the biofilm, become impervious to the host immune defenses and antibiotic therapies. ${ }^{1-3}$ Biofilm-associated infection is still one of the most serious complications of the clinical application of biomedical devices. Both in oral and in orthopedic implantology, implantrelated infections are devastating and expensive events in terms of clinical sequelae and financial costs. In particular, a single episode of arthroplasty infection costs more than $\$ 50,000$ dollars, which can further increase when repeated surgeries are required involving implant replacement and subsequent prolongation of systemic antibiotic therapy, pain, and disability. ${ }^{4}$ Biomaterials are vulnerable to bacterial contamination because the bacteria of the skin and mucosae can come easily in contact with the implant surface during sur- gery, thus having a good chance of adhering to the prosthesis and to cause a deep bone tissue infection. ${ }^{5,6}$ For instance, the occurrence of chronic osteomyelitis after insertion of an external prosthesis is as high as approximately $4 \%,{ }^{7}$ while oral peri-implantitis occurs in $5-8 \%$ of cases within selected implant systems. ${ }^{7-9}$

Infections related to medical devices depend on several factors: chemical-physical properties of the biomaterial, design of the device, anatomical site in which it will be inserted, size of the surface involved, and duration of the surgical procedure. ${ }^{10}$ Worthy of note are the host systemic and local health conditions, as they can counteract or favor bacterial colonization and infection. ${ }^{11}$ Bacteria, fungi, and protozoa can all be enrolled in biomaterial contamination, although the most frequently recovered and documented microorganisms in orthopedic biomaterial infections are host endogenous commensal bacteria, such as Staphylococcus epidermidis and other coagulase-negative staphylococcal 
species, or mild pathogens, such as Staphylococcus aureus. ${ }^{12,13}$ Similarly, oral implants are usually infected by microorganisms belonging to the commensal oral flora. These saprophytes are nonvirulent or less virulent in the planktonic form, but become highly pathogenic when arranged in a biofilm or when the natural microbial balance is lacking. ${ }^{14}$

The events that lead to biofilm formation are key factors to be targeted by preventive strategies. Adhesion is the first infection step allowing bacteria to grow and invade the host tissues. Bacterial adhesion on the implant surfaces can be influenced by aspecific factors, such as van der Waals forces, as well as by specific microbial surface component recognizing adhesive matrix molecules, which are adhesins harbored by the bacterial cell-wall and act as receptors for the host extracellular matrix proteins adsorbed on the implant surfaces. $^{7,15-17}$ After surface colonization by pioneering strains, which are mainly cocci spp. both in the oral cavity (where Streptococcus mutans predominates) and in orthopedics (where the above-mentioned staphylococci, together with Enterococcus faecalis, ${ }^{18}$ are the leading etiologic species), coaggregation of other residing bacteria, either planktonic or adhering, ${ }^{19}$ occurs. They then replicate producing confluent growth and biofilm. This happens on natural hard tissues (either bone or tooth) as well as on polymeric, metallic, and ceramic materials. ${ }^{20-23}$

Material surface too plays a role in these early phases. In particular, surface energy, ${ }^{24}$ micromorphology and roughness, ${ }^{25}$ material stability, crystallographic properties, ${ }^{21}$ and surface chemistry ${ }^{22,26}$ are able to affect the susceptibility to biofilm adhesion and its early development. Therefore, the surface properties of biomaterials could be addressed to inhibit bacterial adhesion and colonization. ${ }^{27}$

Recently, several inorganic antimicrobial agents have been used as a promising strategy to discourage biofilm formation onto implant surfaces by exploiting their known antibacterial properties to reduce both the systemic antibiotic therapy and the surgical procedures necessary to remove the infected implants. ${ }^{3,27,28}$ In particular silver (Ag) and gallium (Ga), a semimetallic element in group $13\left(3^{+}\right)$, have been shown to be effective in the prevention of implant surgical infections. ${ }^{29-35}$ Bacteriostatic/bactericide properties of silver are well known and are mainly due to its multiform mechanisms to damage bacteria even at very low concentrations. ${ }^{34,35}$ More recent is the knowledge of an antibacterial potential of gallium, which is hypothesized to be based on an intriguing "Trojan horse" strategy. ${ }^{32}$

In the present work, we aim at examining the effectiveness of newly designed gallium-based treatments for titanium surfaces in counteracting biofilm formation. Antibiofilm efficacy of the gallium-based modifications was evaluated in vivo in comparison with those of parallel silver-based modifications. We have also evaluated, by means of confocal laser scanning microscopy (CLSM) after Live/Dead staining, the presence and the thickness of the biofilms produced in vitro on the modified materials by $S$. mutans, the most representative cariogenic pathogen of the oral flora.
Moreover, we aimed at ascertaining the cytocompatibility properties of the surface-modified materials, in view of their potential clinical applications in oral implantology and in orthopedics as infection-resistant materials.

In this connection, it could be underlined that a close and firm adhesion of the connective tissues (both noncalcified and calcified) to the prosthesis surface is required to ensure the proper stability of bone orthopedic and oral implants and to protect against bacterial penetration. In fact, a successful biointegration of the implant by the host cells opposes bacteria in the race for the surface. ${ }^{36,37}$ In oral implants a fibrous connective tissue tenaciously anchored to the implant surface, besides nourishing and supplying blood to the underlying bone, is also able to prevent the apical migration of the gingival epithelium, which should seal the implant interface and obstruct bacteria entry. Therefore, resistance to implant infection can certainly be improved by an effective antibiofilm treatment of the implant surface, but a right connective tissue adhesion greatly advantages in preserving the implant from storming bacteria.

These observations are the reason of our efforts in searching for a surface titanium treatment able to hamper bacterial colonization and biofilm formation and, in the meantime, to support valuably the adhesion of the implant surrounding stromal connective tissues. In this perspective, we also tested the modified-materials for their in vitro cytocompatibility with human primary gingival fibroblasts, as a model of behavior of connective cells in contact.

\section{MATERIALS AND METHODS}

\section{Preparation of the titanium samples}

Titanium disks (diameter: $12 \mathrm{~mm}$; thickness: $0.5 \mathrm{~mm}$ ) were obtained by a mechanical cutter from a plate of commercially pure grade 2 titanium (Torresin Titanio Metalli S.r.l., Limena, Italy). Before undergoing any treatment, all the samples were cleaned by ultrasonic rinsing (Elmasonic S 60/H, Elma Hans Schmidbauer, Singen, Germany) in acetone (RPE; Carlo Erba, Rodano, Italy) for $10 \mathrm{~min}$ and afterward rinsed in Millipore water for further $10 \mathrm{~min}$ to remove surface contaminants related to manufacturing and handling. Finally, the samples were dried in a thermostatic oven at $37^{\circ} \mathrm{C}$ for $2 \mathrm{~h}$.

Titanium specimens were then modified with the addition of antibacterial compounds by electrochemical surface modification using the anodic spark deposition (ASD) method as previously reported. ${ }^{38}$ Nontreated grade 2 titanium was always used as further control.

The different antibacterial treatments were developed starting from the same base solution. This solution (called $\mathrm{SiB}$ ) is currently used to produce a biomimetic coating on dental implants. ${ }^{39}$ Specimens treated with $\mathrm{SiB}$ were subjected to an alkali treatment in $5 \mathrm{M} \mathrm{NaOH}$ for $2 \mathrm{~h}$ at $60^{\circ} \mathrm{C} \pm 2^{\circ} \mathrm{C}$. The aim of this alkali etching was to produce a surface sodium enrichment and increase the $\mathrm{Ca} / \mathrm{P}$ (calcium/ phosphorous) ratio. The resulting samples, called SiB-Na, were used as control samples.

The base SiB electrolytic solution contained $0.03 \mathrm{M}$ di$\mathrm{Na}_{2} \mathrm{SiO}_{3} \cdot 2 \mathrm{H}_{2} \mathrm{O}, 0.1 M$ di- $\beta$-glycerophosphate disodium salt 
TABLE I. Experimental Matrix of the Treatments

\begin{tabular}{|c|c|c|c|c|c|c|c|}
\hline Treatment & $\begin{array}{c}\text { Antibacterial } \\
\text { Agent }\end{array}$ & $\begin{array}{l}\text { Antibacterial } \\
\text { Concentration }\end{array}$ & $\begin{array}{l}\text { Chelating } \\
\text { Agent }\end{array}$ & $\begin{array}{c}\text { Chelating } \\
\text { Agent } \\
\text { Concentration } \\
(M)\end{array}$ & $\begin{array}{l}\text { Current } \\
\left(\mathrm{mA} / \mathrm{cm}^{2}\right)\end{array}$ & Potential (V) & $\begin{array}{c}\text { Time of } \\
\text { Treatment (s) }\end{array}$ \\
\hline $\mathrm{SiB}-\mathrm{Na}$ & - & - & & - & 10 & 295 & $\begin{array}{l}776 \pm 120 \\
\mathrm{AT}^{\wedge} 7200\end{array}$ \\
\hline AgCis & $\mathrm{AgNo}_{3}$ & $0.004 M$ & L-Cysteine & 0.002 & 10 & 295 & $690 \pm 30$ \\
\hline $\mathrm{GaCis}$ & $\mathrm{Ga}\left(\mathrm{NO}_{3}\right)_{3}$ & $0.004 M$ & L-Cysteine & 0.006 & 10 & 295 & $700 \pm 12$ \\
\hline GaOss & $\mathrm{Ga}\left(\mathrm{NO}_{3}\right)_{3}$ & $0.004 M$ & oxalic acid & 0.306 & 10 & 325 & $606 \pm 66$ \\
\hline AgNPs & $\begin{array}{l}\text { Silver nanopar- } \\
\text { ticles }(50 \mathrm{~nm})\end{array}$ & $3 \mathrm{~g} / \mathrm{L}$ & - & - & 10 & 295 & $656 \pm 49$ \\
\hline
\end{tabular}

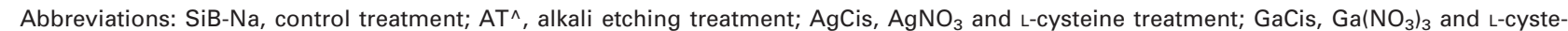
ine treatment; $\mathrm{GaOss}, \mathrm{Ga}\left(\mathrm{NO}_{3}\right)_{3}$ and oxalic acid treatment; AgNPs, silver nanoparticles.

pentahydrate, $0.3 \quad M$ calcium acetate $\cdot \mathrm{H}_{2} \mathrm{O}$, and $0.036 \quad M$ $\mathrm{NaOH}$ (all provided by Sigma-Aldrich, St. Louis, MO). Afterward, antibacterial species and the chelating compounds were added to the SiB solution to produce the final antibacterial treatment.

The antibacterial agents used were silver nanoparticles, silver nitrate, silver acetate, and gallium nitrate (all provided by Sigma) appropriately mixed with L-cysteine and oxalic acid dehydrate (all provided by Sigma-Aldrich) as chelating agents. These latter were used to avoid the massive precipitation of silver and gallium salts in the electrolytic solution, thus improving their migration toward the anode. Table I reports the complete scheme of the tested antibacterial agents, the concentrations of chelating agents, and the electrochemical parameters applied during the ASD treatment.

\section{Morphological and chemical analysis}

Scanning electron microscopy (SEM) was used to investigate the surface morphology of the samples. Briefly, after fixing on aluminum stubs using a conductive carbon tape, samples were observed with a StereoScan 360 SEM (Cambridge Instruments, Somerville, MA) at $10 \mathrm{kV}$ with various magnifications, using secondary electrons. ${ }^{39}$

The chemical qualitative analysis was made by an Energy Dispersive Spectrometer (Inca energy 200; Oxford Instruments, Abingdon, UK) to identify the chemical species present on the surfaces. The analysis was carried out on $500 \times$ acquired images.

\section{Primary human gingival fibroblasts isolation}

Primary human gingival fibroblasts (HGFs) were isolated from a fresh gingival biopsy collected from tissues excised from healthy teeth obtained from orthodontic procedures. The entire tissue was minced with a surgical blade and digested for $45 \mathrm{~min}$ at $37^{\circ} \mathrm{C}$ with a solution of $1 \%$ type I collagenase I (Worthington Biochemical Corporation, Lakewood, NJ), 0.1\% dispase I (Worthington) and 25\% trypsin (Sigma-Aldrich) in a serum-free minimal essential medium alpha modification ( $\alpha$-MEM; Sigma-Aldrich). Afterward, the digested solution was filtered with a $0.45 \mu \mathrm{m}$ pore size in order to remove undigested debris and centrifuged $10 \mathrm{~min}$ at $800 \mathrm{rpm}$. The cellular pellet was then resuspended in
$\alpha$-MEM supplemented with $10 \%$ fetal bovine serum (FBS; Sigma-Aldrich), 1\% antibiotics/antimycotics (penicillin/ streptomycin/gentamycin, Sigma-Aldrich) and the cells were seeded into new polystyrene Petri plates (Sigma-Aldrich) containing fresh medium. Cells were grown up to a maximum of about $80 \%$ confluence and detached with trypsin/ EDTA before use; cells from passages 1 to 3 were used for experiments.

\section{Direct cytocompatibility evaluation}

Twelve millimeter samples were placed into 24-multiwell plates; $2 \times 10^{4}$ cells/sample were seeded onto the surfaces of each sample in a low volume $(200 \mu \mathrm{L})$ and allowed to adhere for $4 \mathrm{~h}$. Afterward, each well was filled with $1 \mathrm{~mL}$ of fresh medium and cell viability was evaluated with the (3-(4,5-dimethylthiazol-2-yl)-2,5-diphenyltetrazolium bromide) colorimetric assay (MTT; Sigma-Aldrich) at $24 \mathrm{~h}, 48$ $\mathrm{h}$, and $72 \mathrm{~h}$. Briefly, $100 \mu \mathrm{L}$ of MTT solution $(3 \mathrm{mg} / \mathrm{mL}$ in PBS) were added to each sample and incubated $4 \mathrm{~h}$ in the dark at $37^{\circ} \mathrm{C}$; the composition of PBS was $137 \mathrm{mM} \mathrm{NaCl}$,

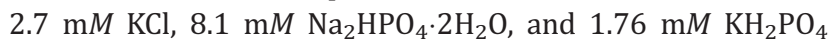
(pH 7.4). Afterward, formazan crystals were solved with $100 \mu \mathrm{L}$ of dimethyl sulfoxyde (DMSO; Sigma-Aldrich) and $50 \mu \mathrm{L}$ were collected and centrifuged to remove any debris.

Supernatant optical density (OD) was evaluated at $570 \mathrm{~nm}$ with a spectrophotometer (Spectra Count, Packard Bell, Meriden, CT). Noncoated titanium OD was used as control and considered as $100 \%$ cell viability while viability of the coated samples was calculated as follows: (sample OD/ titanium control OD) $\times 100$. Experiments were performed six times for controls and each different coating. ${ }^{36}$

Furthermore, immunofluorescence staining was performed in order to investigate cell morphology after $72 \mathrm{~h}$ of adhesion onto the biomaterial surface. Cells were fixed 20 min with $4 \%$ paraformaldehyde at room temperature (RT) and then washed three times with PBS. Phalloidin (rhodamine B tetramethyl isothiocynate, 1/2000 in PBS; AbCam, Cambridge, UK) solution was added for $45 \mathrm{~min}$ at RT in order to investigate the cell cytoskeleton; afterward, samples were washed three times with PBS and costained with 4',6-diamidino-2-phenylindole (DAPI; Sigma-Aldrich). Cell morphology was optically evaluated using fluorescence 


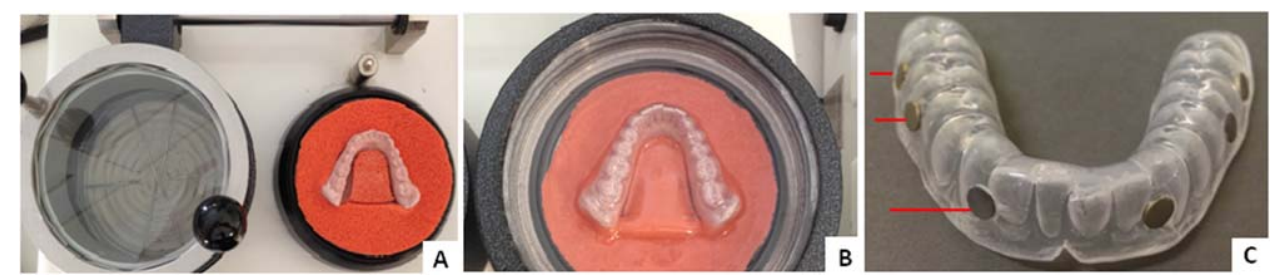

FIGURE 1. Appliances preparation process and chalk footprints (A); polyvinyl chloride (PVC) molds (B); and specimen insertion (C, red arrows). [Color figure can be viewed in the online issue, which is available at wileyonlinelibrary.com.]

microscopy (Leica AF 6500; Leica Microsystems, Basel, Switzerland).

\section{Indirect cytotoxicity evaluation}

Serum free $\alpha$-MEM was incubated without cells for 1 week at $37^{\circ} \mathrm{C}, 5 \% \mathrm{CO}_{2}$ in direct contact with controls or coated samples in a ratio of $1 \mathrm{~mL} / \mathrm{sample}$ for a total of $10 \mathrm{~mL} / \mathrm{specimen}$. Afterward, eluates were collected, supplemented with $10 \%$ FBS and used to cultivate HGFs. Cells were seeded in a definite number $\left(2 \times 10^{4} /\right.$ well) into 24 -well plates (Cell Star; PBI International, Milan, Italy) and cultivated for 1 week at $37^{\circ} \mathrm{C}, 5 \% \mathrm{CO}_{2}$. Afterward, cell viability was evaluated by the MTT colorimetric assay as described for the direct cytocompatibility assay. ${ }^{40}$ Furthermore, cell morphology was visually investigated after 1 week of culture by light microscopy (Leica AF 6500; Leica Microsystems).

\section{In vivo antibacterial activity assessment}

This study was an observational-blind, randomized, intraindividual comparative, and single-center clinical study. The design of the study was in keeping with the ICH note for guidance on Good Clinical Practice (CPMP/ICH/135/95; 1997) and the Declaration of Helsinki (Recommendations Guiding Physicians in Biomedical Research Involving Human Subjects, Helsinki; 1964) and subsequent amendments (1975). Nulla osta was received from the Local Ethics Committee (Novara).

Seven volunteers (four males and three females; age 2027 years, mean age 24 years) gave the informed consent to participate in the study and strictly complied with the prescriptions. Inclusion criteria were: good oral hygiene (plaque index $<10),{ }^{41}$ good health conditions, normal salivary secretion rate (stimulated salivary flow: $2.5+1.24 \mathrm{~mL}$ / min), normal buffer capacity (mean pH value: $6.3+1.72$ ), and absence of marginal gingivitis and active carious lesion; the mean DMFS (Decayed, Missing due to caries, Filled Teeth/Surface) ${ }^{42}$ was 0.6 (range $0-4$ ). Subjects who used antibiotic or chlorhexidine during the 3 months before the study were not included as well as pregnant women.

The volunteers were asked to wear oral appliances for 24 h, shown in Figure 1. These were prepared with polyvinylchloride, containing six specimens (1 mm diameter) and treated as previously described. The different samples were fixed to each appliance in random order as described in Table II.

Volunteers were asked to avoid the use of toothpaste and mouth rinse during the $24 \mathrm{~h}$ and to wear the appliances consecutively with the only exception at meals, when the appliances were stored in saline at RT.

After $24 \mathrm{~h}$, the samples were collected and three samples for each type of coating were used for the colorimetric viability assay (XTT; Sigma-Aldrich) and an additional three for the number counts of the colony forming units (CFU). Briefly, the colorimetric assay 2,3-bis (2-methoxy-4-nitro-5sulfophenyl)-5-((phenyl amino) carbonyl)-2H-tetrazolium hydroxide (XTT; Sigma-Aldrich) was used to determine dehydrogenase activity as an indicator of the metabolic state of the biofilm cells. Disks were transferred into new 24-well culture tissue plates containing $1 \mathrm{~mL}$ PBS/well. Fifty $\mu \mathrm{L}$ XTT solution $(1 \mathrm{mg} / \mathrm{mL}$ in PBS) and $4 \mu \mathrm{L}$ menadione (SigmaAldrich) solution (1 $\mathrm{m} M$ in acetone) were added to each well. Plates were incubated for $5 \mathrm{~h}$ in the dark at $37^{\circ} \mathrm{C}$. The entire content of each well was transferred into new $1.5 \mathrm{~mL}$ Eppendorf tubes and centrifuged (5 min at 13,000 rpm) to

TABLE II. Schematic Representation of Specimen Application onto the Appliance (Sample and Position)

\begin{tabular}{|c|c|c|c|c|c|c|}
\hline \multirow[b]{2}{*}{ Subject } & \multicolumn{6}{|c|}{ Topographic Site For Specimens Insertion } \\
\hline & $4.7-4.6$ & $4.6-4.5$ & $4.3-4.2$ & $3.2-3.3$ & $4.5-4.6$ & $4.6-4.7$ \\
\hline 1 & Ti ctrl & AgNPs & $\mathrm{AgCis}$ & GaCis & GaOss & Ti ctrl \\
\hline 2 & SiB-Na & Ti ctrl & AgNPs & AgCis & Ti ctrl & GaCis \\
\hline 3 & GaOss & $\mathrm{SiB}-\mathrm{Na}$ & Ti ctrl & Ti ctrl & AgNPs & AgCis \\
\hline 4 & $\mathrm{GaCis}$ & Ti ctrl & GaOss & Ti ctrl & SiB-Na & AgNPs \\
\hline 5 & Ti ctrl & AgCis & $\mathrm{GaCis}$ & Ti ctrl & GaOss & SiB-Na \\
\hline 6 & AgNPs & AgCis & Ti ctrl & GaCis & Ti ctrl & GaOss \\
\hline 7 & $\mathrm{SiB}-\mathrm{Na}$ & AgNPs & Ti ctrl & $\mathrm{AgCis}$ & GaCis & Ti ctrl \\
\hline
\end{tabular}

Abbreviation: Ti crtl, untreated titanium.

Each appliance contains one single tested specimen in a random order. The points of insertion are indicated according to the World Dental Federation Numbering System, published as ISO 3950 notation. ${ }^{65}$ 

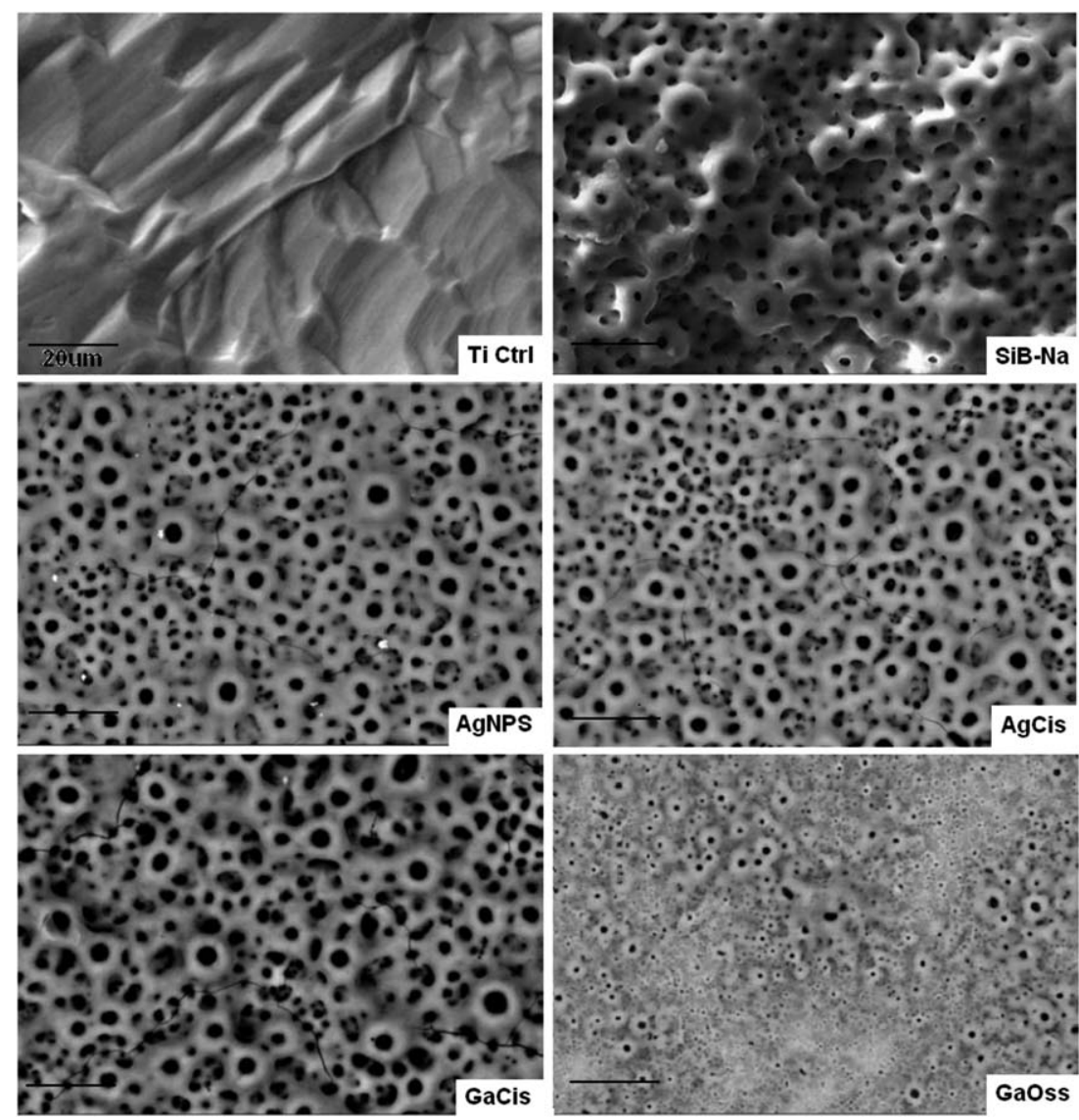

FIGURE 2. SEM images of the different specimens surface at the final stage of preparation. After fixing on aluminum stubs using a conductive carbon tape, samples were observed with a StereoScan $360 \mathrm{SEM}$ at $10 \mathrm{kV}$, using secondary electrons. Magnification $=1500 \times$, bar scale $=20 \mu \mathrm{m}$. In AgNPs specimen small silver nanoparticle aggregates are present as white spots.

remove residual cells. One hundred microliters were transferred from each tube to a new 96-well plate and the XTT formazan in the supernatant was determined spectrophotometrically at $690 \mathrm{~nm}^{43}$

For the CFU counts, disks were resuspended in $1 \mathrm{~mL}$ of PBS, vortexed, and sonicated at $60 \mathrm{~Hz}$ (Aquasonic 250HT; VWR International, Radnor, PA) for $30 \mathrm{~s}$, five times for each sample, to allow the detachment of biofilm from the surface of the disks. One hundred microliter suspensions were transferred to a 96-well plate and used to perform six 10fold dilutions by mixing $20 \mu \mathrm{L}$ of biofilm suspension with $180 \mu \mathrm{L}$ of PBS. Twenty microliters of each dilution were spotted on nutrient agar plates and incubated for $72 \mathrm{~h}$ at $37^{\circ} \mathrm{C}$. Finally, the number of CFUs/disk was counted, in a blinded manner, using the following formula: (number of colonies $) \times 10 \times(\text { reverse of dilution value })^{44}$

\section{In vitro antibiofilm activity assessment}

In vitro biofilm growth. Specimens were sterilized in $70 \%$ ethanol in water for $20 \mathrm{~min}$ and washed extensively with sterile deionized water. A single colony of the $S$. mutans reference strain ATCC 25175 from an overnight culture on agar plate was resuspended in $9 \mathrm{~mL}$ of Tryptose Broth (TB, Biolife, Milan, Italy) and incubated at $37^{\circ} \mathrm{C}$ for $18 \mathrm{~h}$. After incubation, a new fresh TB tube diluted 1:10 was prepared. The new tube was incubated at $37^{\circ} \mathrm{C}$ for $3 \mathrm{~h}$ in order to achieve the logarithmic growth phase. At the end of the incubation period the bacterial suspension was read by a Nephelometer Hach 2100 AN (Hach Lange, Manchester, England). The bacterial suspension was adjusted to obtain a final turbidity of 10 nephelometric turbidity units (NTU). Aliquots of the dilute bacterial suspension were dispensed into 24-well Microplates (Costar, Corning, N Y), each well containing a material specimen (Ti Ctrl, SiB-Na, AgCis, AgNPs, GaCis, and GaOss) and then incubated for $24 \mathrm{~h}$ and $72 \mathrm{~h}$ at $37^{\circ} \mathrm{C}$. During the 72 -h incubation, half culture broth of each well was substituted with fresh TB every day.

CLSM observations. CLSM observations aimed at detecting viability of bacteria grown for $24 \mathrm{~h}$ and $72 \mathrm{~h}$ at $37^{\circ} \mathrm{C}$ on the six different materials. To determine the viability of bacteria a Live/Dead BacLight bacterial viability kit (Molecular Probes, Life Technologies Italia, Monza, Italy) was used. The kit includes two fluorescent nucleic acid stains: SYTO9 and propidium iodide. SYTO 9 penetrates and stains both viable and nonviable bacteria, while propidium iodide enters only damaged/dead cells and quenches SYTO9 fluorescence. Dead cells, which take up propidium iodide, fluoresce red, 


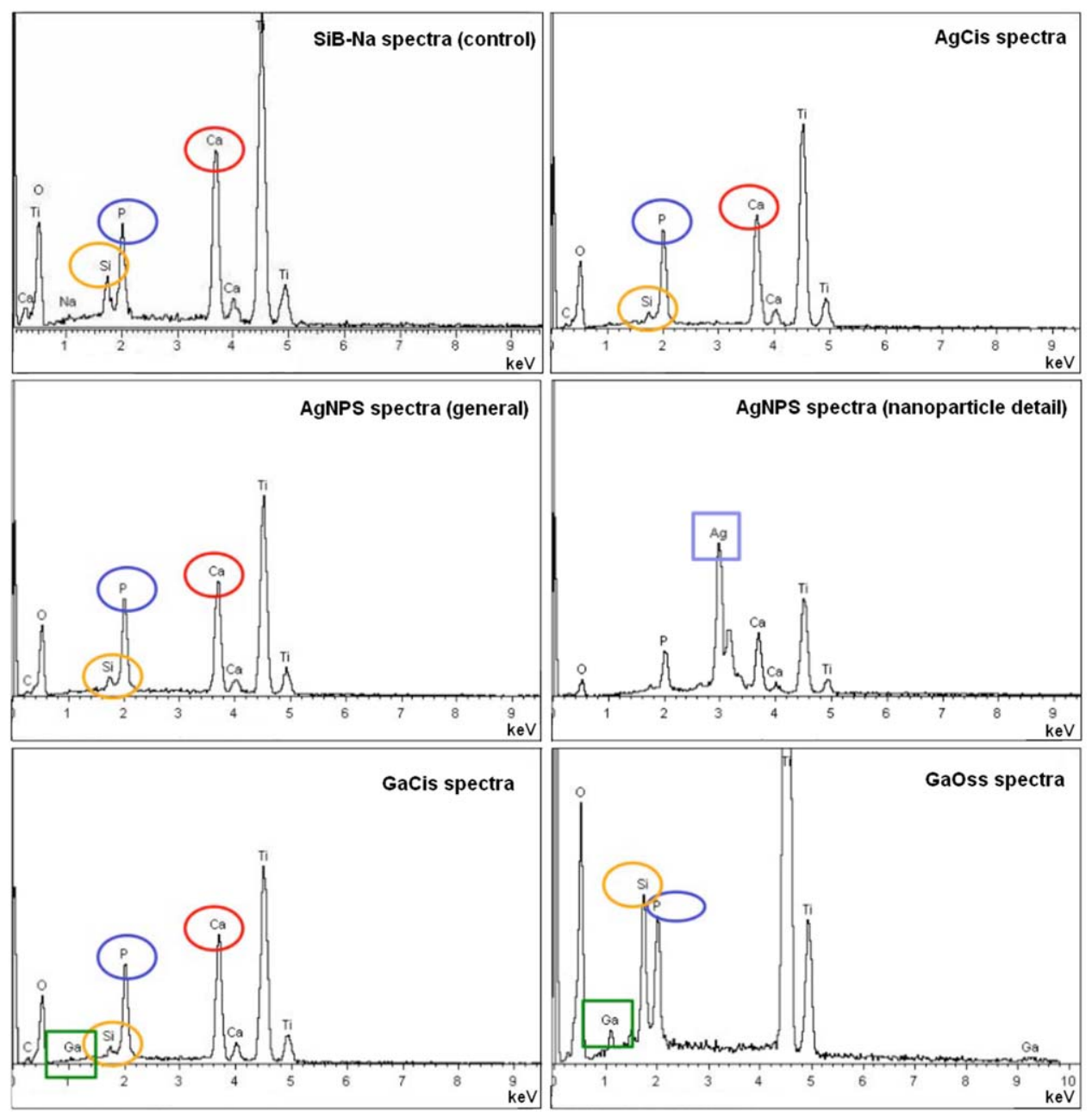

FIGURE 3. Qualitative chemical surface composition spectra (EDS). The EDS spectra highlighted the presence of calcium, phosphorous, and silicon for the SiB-Na control and for all the ASD coatings except for GaOss, for which the calcium signal was undetectable, although the maximum silicon peak was present. [Color figure can be viewed in the online issue, which is available at wileyonlinelibrary.com.]

green cells fluoresce green. For assessing viability, $1 \mathrm{~mL}$ of stock solution of each stain was added to $3 \mathrm{~mL}$ of PBS and, after mixing, the solution was distributed into the plates containing the materials specimens and incubated at RT for 15 min in the dark. Stained biofilms were examined by the Confocal Laser Scanning Microscopy Nikon Eclipse Ti inverted microscope equipped with an AR1 confocal unit, using a 100x oil immersion objective. The excitation and emission wavelengths used for detecting SYTO9 were $488 \mathrm{~nm}$ and $525 \mathrm{~nm}$, respectively. Propidium iodide was excited at $520 \mathrm{~nm}$, and its emission was monitored at $620 \mathrm{~nm}$. Optical sections of $1.0 \mu \mathrm{m}$ were collected from the entire thickness of the biofilm. For each sample, images from three randomly selected positions were acquired. The resulting stacks of images were analyzed using NIS-elements AR 3.2 software confocal software.

\section{Statistical analysis}

Statistical analyses were performed using Statistical Package for Social Sciences (SPSS v20.0, IBM Co. Armonk, NY). The assumptions of homogeneity of variances and normal distri- bution of errors were checked for all the variables considered using Levene's and Kolmogorov-Smirnov tests, respectively. Since the assumptions were satisfied, analysis of variance one-way and post hoc Sheffe's test were used. The significance level was set at $5 \%$.

\section{RESULTS}

\section{Morphological and chemical evaluation}

SEM images are reported in Figure 2. All the different coatings proved to be very stable and homogeneously distributed on the sample surfaces. The untreated titanium (Ti ctrl) surface did not appear to be particularly smooth and it was characterized by a raw "flake" morphology. In general, the ASD-treated surfaces showed a very similar morphology, with micrometric pore size and characterized by homogeneous pore distribution. A different morphology is displayed by the GaOss treatment, in which the pore diameter is smaller than the other ASD coatings and it is characterized by an irregular pore size distribution (Fig. 2). It is interesting to observe that some microcracks were detectable especially on AgNPs, AgCis, and GaCis treatments, which are 


\section{Direct Cytocompatibility Assay}

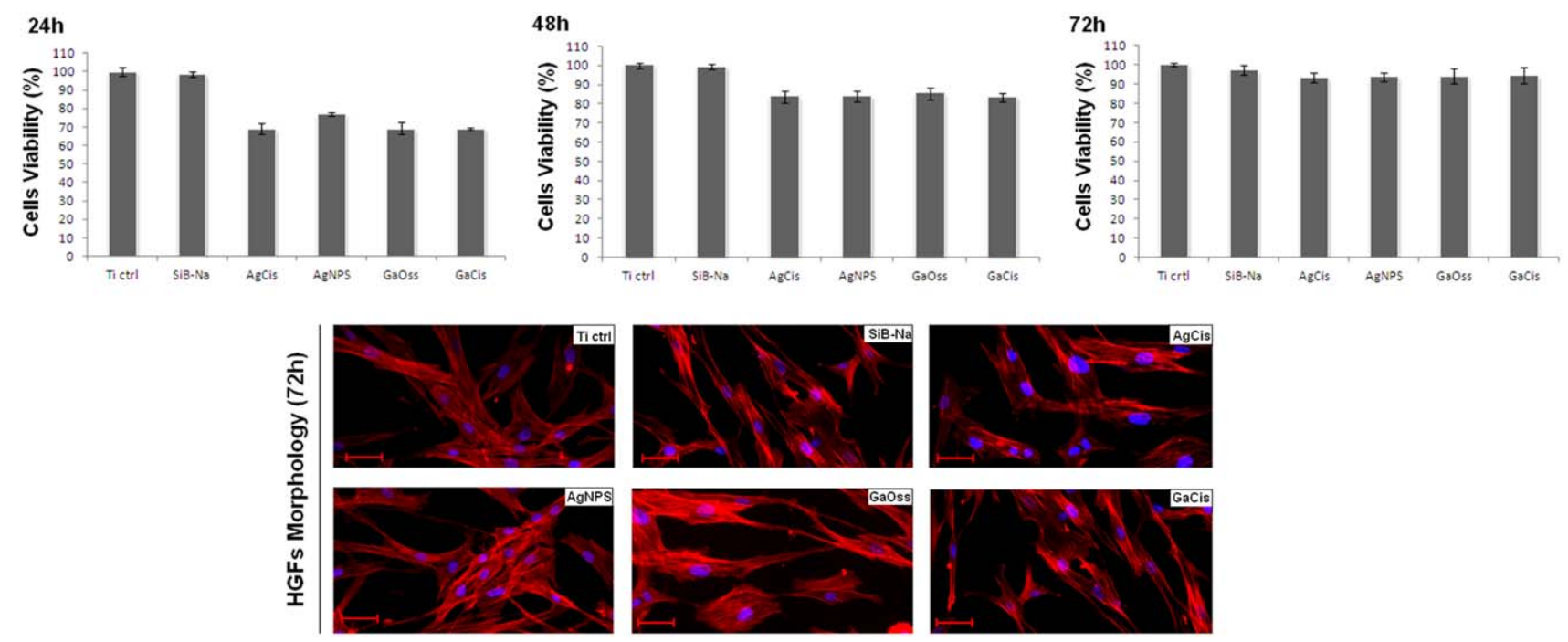

FIGURE 4. Direct cytocompatibility assay. Histograms (upper panel) represent cells viability after $24 \mathrm{~h}, 48 \mathrm{~h}$, and $72 \mathrm{~h}$ of direct culture onto specimen surfaces. Bars represent means and standard deviations; no statistically significant values were observed in the lower panel, immunofluorescence staining of phalloidin (red) and DAPI (blue) shows a physiological cellular adhesion and morphology without remarkable differences between controls and tested samples after $72 \mathrm{~h}$. Bar scale $=50 \mu \mathrm{m}$.

commonly present on the ASD treatments, but not representative of the coating's poor adherence or susceptibility to delamination. No cracks were visible on SiB-Na (control) and on GaOss treatment. AgNPs specimen clearly showed the presence of small silver nanoparticle aggregates identifiable by the presence of white spots (Fig. 2).

Chemical qualitative analysis [energy dispersive X-ray spectroscopy (EDS)] results are reported in Figure 3. The EDS spectra highlighted the presence of the chemical elements showing on the SiB-Na control such as calcium, phosphorous, and silicon for all the ASD coatings except for GaOss, for which the calcium signal was undetectable, although the maximum silicon peak was present. The presence of calcium, phosphorous, and above all of silicon played a fundamental role in enhancing the mineralization process of the ASD coating. ${ }^{39}$ In particular, the SiB-Na surface also showed the presence of sodium, ascribed to the etching treatment performed after the ASD treatments. For the EDS spectra of the ASD coating, performed in the electrolytic solutions enriched with silver (AgNPs and AgCis), there was no detectable silver presence. Only by performing a careful EDS analysis where SEM images showed a white spot, it was possible to confirm the integration of silver within AgNPs surface. GaCis and GaOss spectra revealed gallium presence on surfaces; the gallium peak on GaOss, in particular, was higher than those observed in the GaCis samples.

\section{Cytocompatibility testing}

The in vitro biological tests revealed the absence of any direct or indirect cytotoxic effect for any of the investigated materials (Figs. 4 and 5). For all the tested time-points, the direct cytocompatibility test reported a cell viability between $70 \%$ and $97 \%$ compared to controls (100\%). The mean values of viability expressed as cells/surface were $10-12$ cells $/ \mathrm{mm}^{2}$ for all the materials. Furthermore, immunofluorescence staining of cells, seeded directly onto the sample surfaces, revealed a physiological cellular adhesion and morphology without remarkable differences between controls and tested samples (Fig. 4). It should also be underlined that pictures shown in Fig. 4 were intentionally taken from regions where the cell density was lower, in order to focus on single cell morphology, rather than from high-density regions, where distinct cell morphology could not be appreciated.

The indirect cytotoxicity assay excluded any negative effects for the cells cultured in contact with the medium previously incubated for 1 week in contact with the treated materials. Cell viability was in a range of $90-95 \%$ compared to cells cultivated with fresh medium. Very good cellular viability was also confirmed by microscopy analysis that showed perfect cellular morphology when cells cultivated with test media were compared with control ones (Fig. 5).

\section{Antibacterial activity}

All of the tested specimens possessed a significant reduction in bacterial viability compared to untreated titanium $(p<0.05)$ in both the CFU (A) and the XTT (B) assays as shown in Figure 6(A,B). More specifically, gallium-based samples showed the best bactericidal activity among the antibacterial treatments developed. In fact, the values of $\mathrm{CFU} / \mathrm{mm}^{2}$ were reduced by about $48 \%$ with GaCis $\left(\log _{10}\right.$ 3.920 ) and by $40 \%$ with GaOss ( $\left.\log _{10} 3.982\right)$, when compared with the control SiB-Na, $\left(\log _{10} 4.161\right)$, while the samples containing silver displayed a bacterial inhibition of 

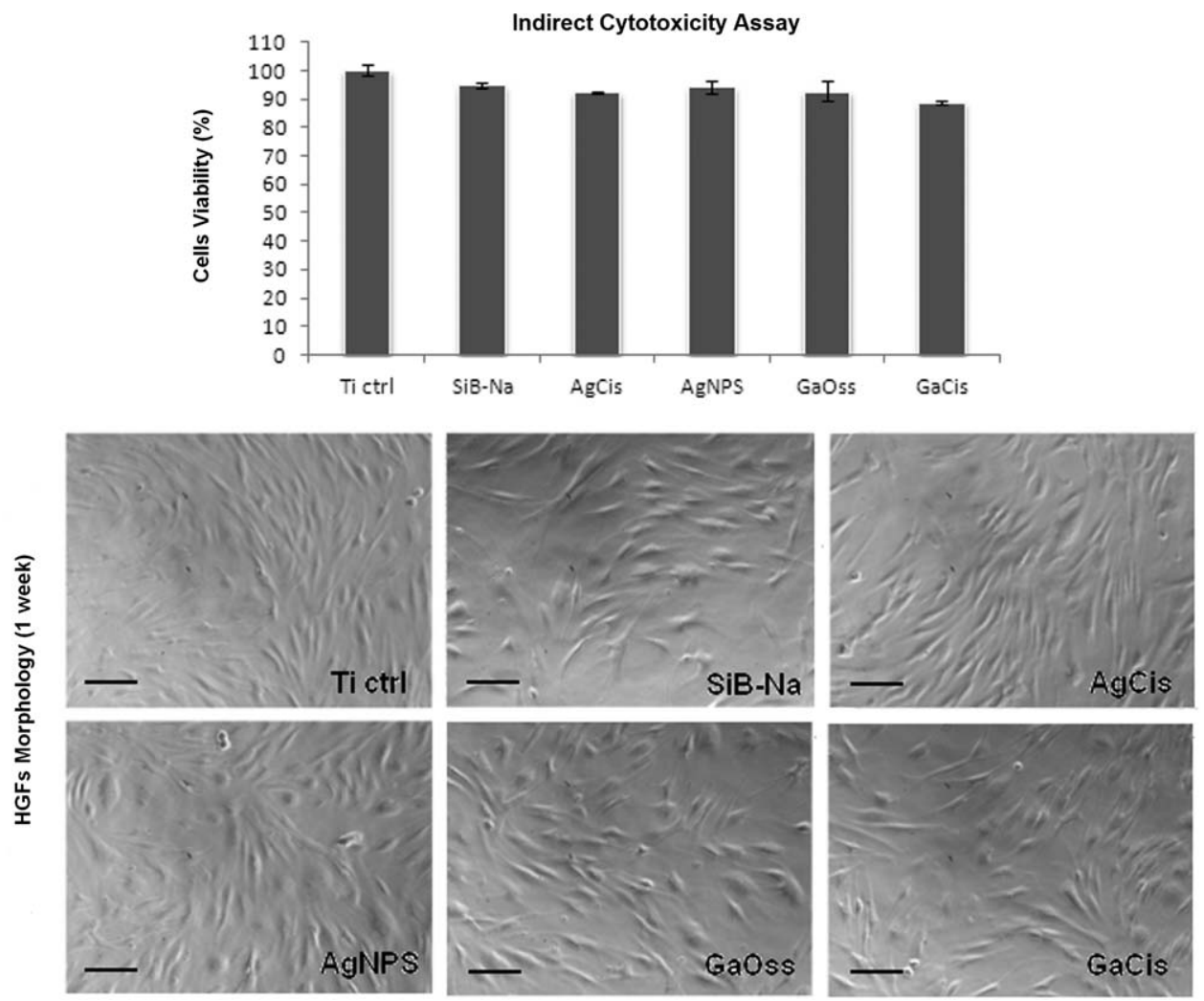

FIGURE 5. Indirect cytotoxicity assay. After 1 week of culture with eluates, cells viability results comparable with controls. Bars represent means and standard deviations. In the lower panel, microscopy observation shows cell morphology; no statistical differences were found between controls and test samples. Bar scale $=100 \mu \mathrm{m}$.

about $30 \%$ (AgCis $\log _{10} 4.047$ ) to $34 \%$ [AgNPs $\log _{10} 4021$; Fig. 6(A)].

CFU counts were confirmed by the XTT viability assay: bacteria viability on gallium-treated samples as measured by the inhibition ratio was in a range between $27 \%$ (GaOss) and $35 \%$ (GaCis) compared to controls. Silver samples confirmed CFU results, but with a slightly lower inhibition ratio than gallium [Fig. 6(B)].

\section{In vitro antibiofilm activity}

Presence and thickness of the biofilms on the six materials were evaluated by CLSM after Live/Dead staining. Figure 7 shows that after a 24-h culture $S$. mutans was growing in its typical twisted fine chains only on Ti ctrl and SiB-Na specimens, while no bacterial colonies could be observed on the other specimens.

Figure 8 shows that, after a 72-h culture, an abundant biofilm was produced on Ti Ctrl and on SiB-Na disks. The percentages of live and dead cells were calculated by the NIS-elements AR 3.2 confocal software, measuring the fluorescence intensities of green and red channels. On the $\mathrm{Ti}$ Ctrl disk, 55\% of cells appeared live and 45\% dead. On the SiB-Na disk the number of cells was slightly lower and, from the intensities of the red and green channels, $45 \%$ of
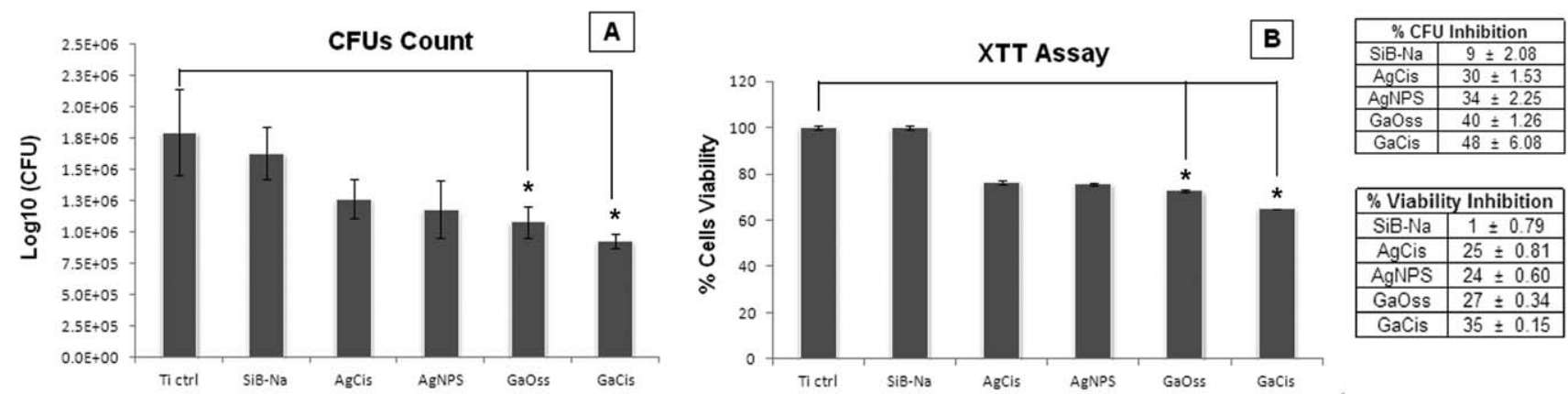

FIGURE 6. Antibacterial activity of the specimens. The number of CFUs was significantly reduced by GaCis (A). Also bacterial viability was significantly reduced by gallium samples ( $\mathrm{GaOss}$ and $\mathrm{GaCis)}$ as reported by the XTT assay (B). Asterisks represent statistically significant values $(p<0.005)$. 

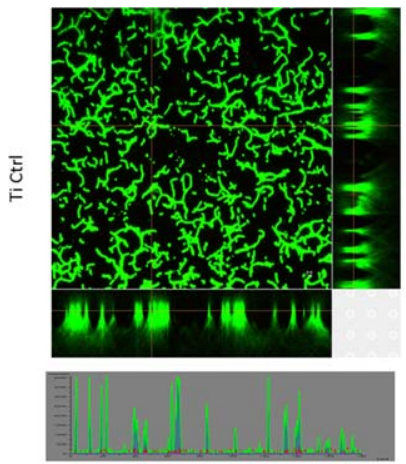

Ti Ctrl Fluorescence Intensity. 15884 live cells; 2245 dead cells
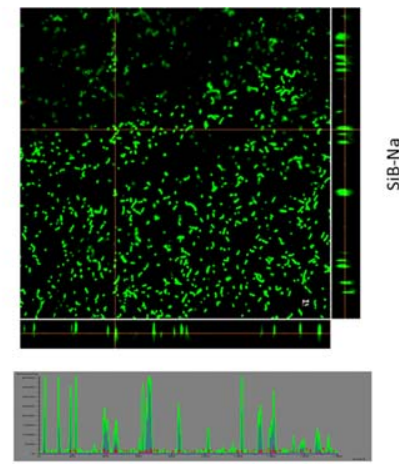

SiB-Na Fluorescence Intensity. 13274 live cells; 5683 dead cells

FIGURE 7. CLSM images of $S$. mutans 24-h-old biofilms grown on $\mathrm{Ti}$ Ctrl and SiB-Na disks. Live bacteria are stained in green (SYTO9) and dead bacteria in red (propidium iodide) or yellow (overlapping regions). By means of the Intensity Profile function of the NISELEMENTS AR 4.10.04 software a quantitative estimation of live and dead cells was calculated.

the cells appeared live and 55\% dead. Surprisingly, while well-developed biofilms were observed on the Ti Ctrl and SiB-Na disks, on the materials modified by the antibacterial treatments, neither biofilms nor even adherent bacteria were detected. These results clearly indicate that the Agand Ga-modified materials, which exhibited in vivo a lower colonization by the polymicromial oral flora in the mouth environment, behaved like strong antiadhesive, bacterial repellent surfaces when in vitro tested against the single species $S$. mutans in a broth medium.

\section{DISCUSSION}

Owing to their good mechanical properties and their excellent biocompatibility, titanium and titanium alloys represent the materials of choice for applications in contact with bone. Unfortunately, an implant infection may occur, ${ }^{45}$ together with the corollary of the implant failure. Interestingly, failure is defined "the inadequacy of the host tissues to establish or maintain implant biointegration." ${ }^{9}$ Thus, infection, lack/loss of implant integration, mobilization, and failure appear to be unfavorably events closely connected.

In recent years, different surface treatments have been developed in order to produce antibacterial coatings on titanium and its alloys. Among many different surface modification techniques available today to produce biomimetic coatings on titanium and titanium alloys, ASD offers the advantage of obtaining mechanically stable and reproducible coatings on 3D complex geometries, such as those of dental implants or joint prostheses, enabling to achieve a very thin layer with advanced modulation of the chemical composition and topographic structure. For these reasons, ASD is one of the most versatile and powerful treatments for orthopedic and dental implant applications. ${ }^{46}$ Moreover, ASD overcomes the drawbacks deriving from coating delamination, due to limited coating adherence. ASD treatments were performed in different electrolytic solutions containing sil-

ver and gallium, which are known to express bactericidal properties against a significant variety of pathogens (such as bacteria, fungi, and viruses) without evoking microbial resistance, unlike what is occurring today with a large number of antibiotics being used. ${ }^{47}$

The developed biomimetic antibacterial ASD treatments were found to provide a homogeneous microporous morphology, which is a desired feature, known to positively influence human cell attachment, spreading, proliferation, and differentiation. Reports from the literature ${ }^{48-54}$ show that the presence of micropores can also greatly enhance osteointegration and play a role in controlling the steps of cell adhesion, proliferation, and differentiation. Moreover, it has been pointed out that porosity, as well as roughness, ${ }^{24,25,55,56}$ can modulate the behavior of cells in contact. For instance, the presence of a porous structure increases in
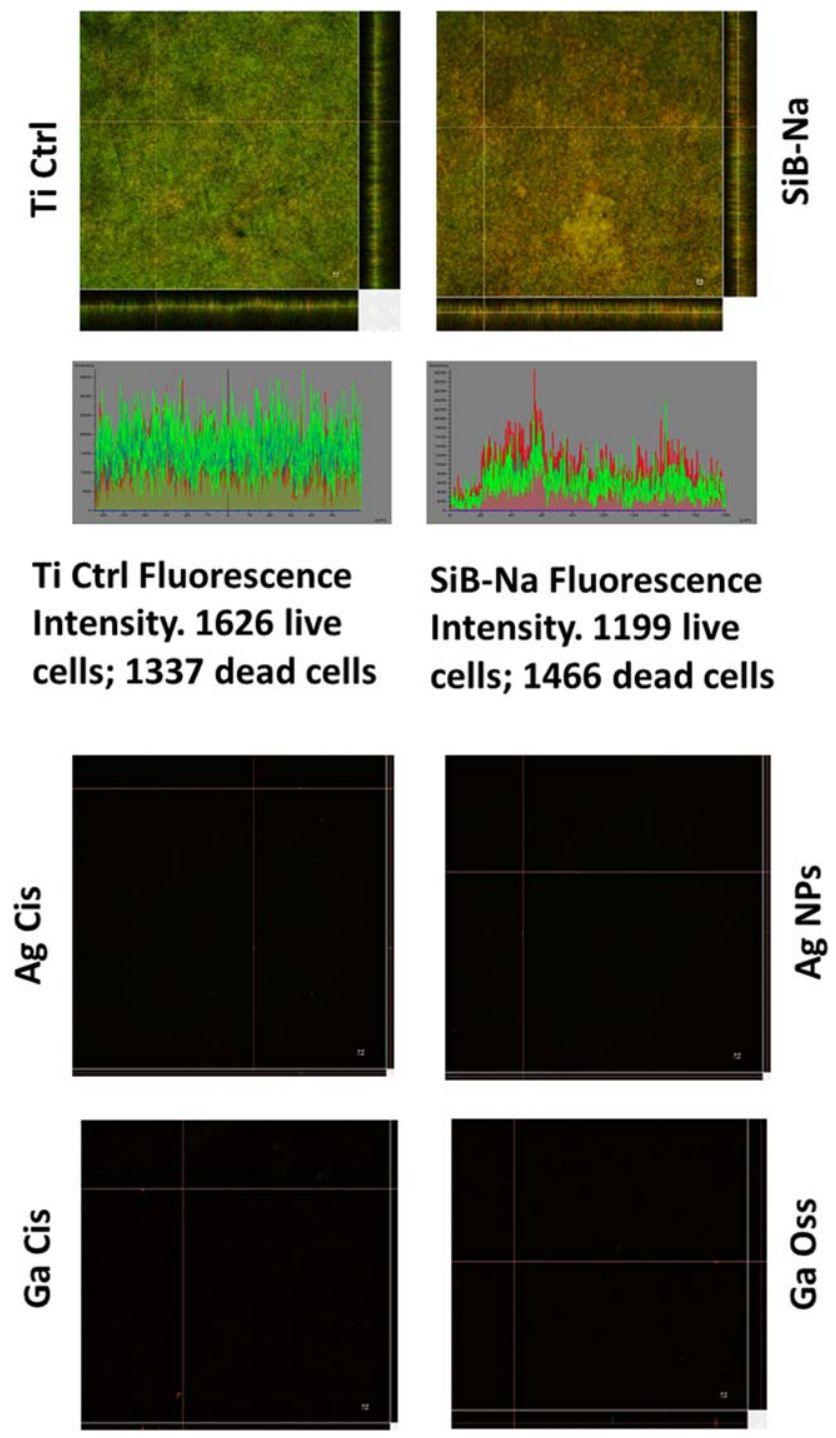

FIGURE 8. CLSM images of $S$. mutans 72-h-old biofilms grown on $\mathrm{Ti}$ Ctrl, SiB-Na, AgCis, AgNPs, GaCis, and GaOss disks. Only on Ti Ctrl and SiB-Na a biofilm was detectable. On the remaining disks neither single colonies nor biofilm were visible. Staining and calculation of live and dead cells was as in Figure 7. 
vivo bone-to-implant contact, improving the mechanical interlocking of the bone bonding. Noticeably, the GaOss treatment revealed different pore diameters which are smaller than those of the other studied ASD coatings, probably due to the different chelating compound used (compared to GaCis treatment) and to the different voltage reached by the coating during the ASD process (325 vs. $295 \mathrm{~V}$ ).

Cytocompatibility testing revealed that the different treatments were compatible with the cells. In both direct and indirect assays, results suggested that the modification by the ASD treatment did not introduce toxic elements into the specimens at the released concentrations. Small, nonsignificant, differences of viability values between ASDmaterials and controls were observed in the MTT direct cytocompatibility assays at 24 . The viability values of ASDmaterials were higher at $48 \mathrm{~h}$ and completely comparable to those of controls at $72 \mathrm{~h}$, when gingival fibroblasts fully adhered and spread on modified materials.

It should be remarked that two different types of cytotoxicity assays were performed. The results of the indirect cytotoxicity assay after 1 week of cultivation with eluates (Fig. 5) shows that results were comparable with controls: no statistical differences were found between controls and test samples. In the lower panel of Figure 5, microscopy observations, showing the cell morphology, support the statistical result of an absence of remarkable differences.

Results suggest that the viable and adherent gingival fibroblasts observed in the in vitro model can be expected to be able to form in vivo a connective tissue healthily sustaining the gingival epithelium. Therefore, epithelium will act as an effective barrier against the colonization by the oral flora. In a different way, when epithelium is not properly supported by the connective tissue, a gingival recession can occur that leads to the formation of a tissue pocket prone to the microbial contamination. Then bone resorption and mobilization of the implant intervene. ${ }^{57}$

The results of in vivo inhibition of biofilm bacteria cells are very promising. In general, CFU counts showed a reduction in bacterial colonies on the treated samples compared with the controls. Silver-coated samples resulted in 30-34\% decrease in bacterial colonies compared to the controls. These results confirm the antibacterial properties of silver, which is known to be able to damage bacterial cells membranes, interfere in ion transport, denaturate enzymes, and inhibit DNA transcription and cellular respiration. More specifically, $\mathrm{Ag}^{+}$ions interact with thiol groups in proteins and inhibit respiratory enzymes, resulting in the production of reactive oxygen species. ${ }^{34,35}$

The study was performed in vivo since it was addressed to the effect of gallium against the human oral microbiome, which comprises over 500 bacterial species. ${ }^{58}$ An in vitro study would have necessarily limited the use of bacteria to one or a few biofilm forming species, such as $S$. mutans ${ }^{59}$ and Aggregatibacter actinomycetemcomitans, ${ }^{60}$ which would not have been able to reproduce in vitro the biofilm formed in vivo by the several hundred species of bacteria of the human oral polymicrobial flora. ${ }^{61}$
Recently, the effect of gallium on the growth of the biofilm was studied in vitro by CFU counting of biofilm viable Pseudomonas aeruginosa cells detached from disks of gallium-carboxymethyl cellulose after different incubation times. Gallium-carboxymethyl cellulose was found to reduce by $15 \%$ the biofilm growth of $P$. aeruginosa at $24 \mathrm{~h}$ in respect to sodium-carboxymethyl cellulose. ${ }^{62}$ In our in vivo study, biofilm was evaluated by a CFU counting method similar to that used in Ref. [62. After 24 h-appliance to GaCis disks, a $48 \%$ biofilm reduction was found, greater than that observed by Valappil et al. ${ }^{62}$

More interesting results were obtained with galliumcoated specimens, which showed higher values of inhibition ( $40 \%$ and $48 \%$ ) compared to the controls. The antibacterial properties of gallium have been recently highlighted. At $\mathrm{pH}$ values close to neutral, the free hydrated $\mathrm{Ga}^{3+}$ ion hydrolyzes forming highly insoluble amorphous Ga species $(\mathrm{OH})^{3}$. The $\mathrm{Ga}^{3+}$ is a hard acid that strongly binds in solution Lewis bases, particularly $\mathrm{OH}^{-}$groups. Furthermore, gallium tends to generate chelates by binding oxygen and also nitrogen atoms. ${ }^{29}$

From a metabolic point of view, $\mathrm{Ga}^{3+}$ is very similar to $\mathrm{Fe}^{3+}$, and acts as an iron substitute in many biological pathways. $^{30,31}$ It is precisely thanks to the chemical similarity of $\mathrm{Ga}^{3+}$ with $\mathrm{Fe}^{3+}$, in terms of charge, ionic radius, electronic configuration, and coordination number, that gallium can substitute iron in the biological systems, thus carrying out its antibacterial effect. Indeed, since $\mathrm{Ga}^{3+}$ cannot be reduced under the same conditions as $\mathrm{Fe}^{3+}$, sequential redox reactions critical for the biological functions of $\mathrm{Fe}^{3+}$ are impaired by the iron substitution with gallium. Therefore, gallium inhibits $\mathrm{Fe}^{3+}$ biological functions by a "Trojan horse" strategy. ${ }^{30-32}$ This strategy can be exploited to interfere with or disrupt the iron metabolism in a large number of bacterial strains, including $P$. aeruginosa, ${ }^{30}$ Mycobacteria $^{32}$ Clostridium difficile, and the methicillin-resistant $S$. aureus. $^{33}$

This general trend was also confirmed by XTT analysis. A reduction in the metabolic activity was observed in gallium- and silver-treated specimens, with the best inhibition ratio in the gallium specimens (27-35\%). These values are particularly significant since volunteers did not use any toothpaste or mouth rinse during the trial. Thus, the inhibition can be related only to the silver and gallium treatments.

In two very recent in vitro studies, dealing with the detachment of bacterial biofilms from disks, either by fluid for oral rinses or by solutions of $\mathrm{N}$-chlorotaurine for surgical irrigations, the antimicrobial/antibiofilm effects were evaluated by the XTT assay for bacterial metabolic activity, by live/dead staining, as well as by CFU counting. ${ }^{63,64}$ Live/ dead staining did not apply to our in vivo study, since after 24-h of oral application of the disks, besides bacteria, also epithelial cells exfoliating from the mouth mucosae could have adhered onto the disks, thus altering the results.

Although the specimens were worn only for a relatively short time $(24 \mathrm{~h})$, it should be remarked that none of the volunteers presented signs of adverse effect toward the 
tested materials. Seen on the whole, these findings suggest that gallium may represent a valid antibacterial agent for the prevention of implant contamination.

The results of in vitro biofilm production by $S$. mutans have shown that even after 72-h culture the Ag- and Gamodified disks still exhibited antiadhesive properties in many times repeated observations. While on the control and on biomimetic titanium disks $S$. mutans produced biofilms with appreciable thickness, on the Ag- and Ga-modified materials neither biofilms nor bacterial colonies were observed.

\section{CONCLUSION}

This work demonstrates the possibility of successfully using the ASD method to develop biomimetic treatments on titanium substrates, in order to obtain a promising material with antimicrobials properties and with a good tissueintegrative potential.

\section{ACKNOWLEDGMENTS}

The authors would like to thank Massimo Cavallo and Simone Stroppa for the excellent technical support. Special thanks to Eurocoating S.p.A. (Trento, Italy) for their precious cooperation. Many thanks to Doctor Stefano Ravaioli, PhD, postdoc fellow at the Rizzoli Orthopaedic Institute, for his skillful and refined support for the CLSM analysis. The authors express their greatest thanks to Professor Lucio Montanaro (Rizzoli Orthopaedic Institute) for his masterly suggestions and for critical reading the article.

\section{REFERENCES}

1. Zimmerli W, Trampuz A, Ochsner PE. Prosthetic-joint infections. N Engl J Med 2004;351:1645-1654.

2. Darouiche RO. Treatment of infections associated with surgical implants. N Engl J Med 2004;350:1422-1429.

3. Arciola CR, Campoccia D, Speziale P, Montanaro L, Costerton JW. Biofilm formation in Staphylococcus implant infections. A review of molecular mechanisms and implications for biofilm-resistant materials. Biomaterials 2012;33:5967-5982.

4. Berbari EF, Hanssen AD, Duffy MC, Steckelberg JM, Ilstrup DM, Harmsen WS, Osmon DR. Risk factors for prosthetic joint infection: Case-control study. Clin Infect Dis 1998;27:1247-1254.

5. Zhao L, Chu PK, Zhang Y, Wu Z. Antibacterial coatings on titanium implants. J Biomed Mater Res B Appl Biomater 2009;91: 470-480.

6. Zlowodzki M, Prakash JS, Aggarwal NK. External fixation of complex femoral shaft fractures. Int Orthop 2007;31:409-413.

7. Berglundh T, Persson L, Klinge B. A systematic review of the incidence of biological and technical complications in implant dentistry reported in prospective longitudinal studies of at least 5 years. J Clin Periodontol 2002;29:197-212.

8. Quirynen M, De Soete M, van Steenberghe D. Infectious risks for oral implants: A review of the literature. Clin Oral Implants Res 2002;13:1-19.

9. Pye AD, Lockhart DEA, Dawson MP, Murray CA, Smith AJ. A review of dental implants and infection. J Hosp Infect 2009;72: 104-110.

10. Campoccia D, Montanaro L, Arciola CR. A review of the clinical implications of anti-infective biomaterials and infection-resistant surfaces. Biomaterials 2013;34:8018-8029.

11. Seneviratne CJ, Jin L, Samaranayake LP. Biofilm lifestyle of Candida: A mini review. Oral Dis 2008;14:582-590.

12. Montanaro L, Speziale P, Campoccia D, Ravaioli S, Cangini I, Pietrocola G, Giannini S, Arciola CR. Scenery of Staphylococcus implant infections in orthopedics. Future Microbiol 2011;6:13291349. doi: $10.2217 / \mathrm{fmb}$.11.117.
13. von Eiff C, Arciola CR, Montanaro L, Becker K, Campoccia D. Emerging Staphylococcus species as new pathogens in implant infections. Int J Artif Organs 2006;29:360-367.

14. Chen L, Wen YM. The role of bacterial biofilm in persistent infections and control strategies. Int J Oral Sci 2011;3:66-73.

15. Speziale P, Pietrocola G, Rindi S, Provenzano M, Provenza G, Di Poto A, Visai L, Arciola CR. Structural and functional role of Staphylococcus aureus surface components recognizing adhesive matrix molecules of the host. Future Microbiol 2009;4:1337-1352.

16. Yang L, Liu Y, Wu H, Hóiby N, Molin S, Song ZJ. Current understanding of multi-species biofilms. Int J Oral Sci 2011;3:74-81.

17. Foster TJ, Geoghegan JA, Ganesh VK, Höök M. Adhesion, invasion and evasion: The many functions of the surface proteins of Staphylococcus aureus. Nat Rev Microbiol 2014;12:49-62.

18. Arciola CR, Baldassarri L, Campoccia D, Creti R, Pirini V, Huebner J, Montanaro L. Strong biofilm production, antibiotic multiresistance and high gelE expression in epidemic clones of Enterococcus faecalis from orthopaedic implant infections. Biomaterials 2008;29:580-586.

19. Wessel SW, Chen Y, Maitra A, van den Heuvel ER, Slomp AM, Busscher HJ, van der Mei HC. Adhesion forces and composition of planktonic and adhering oral microbiomes. J Dent Res 2014;93: 84-88.

20. Brambilla E, Ionescu A, Gagliani M, Cochis A, Arciola CR, Rimondini L. Biofilm formation on composite resins for dental restorations: An in situ study on the effect of chlorhexidine mouthrinses. Int J Artif Organs 2012;35:792-799.

21. Giordano C, Saino E, Rimondini L, Pedeferri MP, Visai L, Cigada A, Chiesa R. Electrochemically induced anatase inhibits bacterial colonization on titanium grade 2 and Ti6Al4V alloy for dental and orthopedic devices. Colloids Surf B Biointerfaces 2011;88:648-655.

22. Visai L, Rimondini L, Giordano C, Del Curto B, Sbarra MS, Franchini R, Della Valle C, Chiesa R. Electrochemical surface modification of titanium for implant abutments can affect oral bacteria contamination. J Appl Biomater Biomech 2008;6:170-177.

23. Rimondini L, Cerroni L, Carrassi A, Torricelli P. Bacterial colonization of zirconia ceramic surfaces: An in vitro and in vivo study. Int J Oral Maxillofac Implants 2002;17:793-798.

24. Rimondini L, Farè S, Chiesa R, Pedeferri MP, Carrassi A. The effect of composition, wettability and roughness of the substrate on in vivo early bacterial colonization of titanium. J Appl Biomater Biomech 2003;1:131-138.

25. Rimondini L, Farè S, Brambilla E, Felloni A, Consonni C, Brossa F, Carrassi A. The effect of surface roughness on early in vivo plaque colonization on titanium. J Periodontol 1997;68:556-562.

26. Petrini P, Arciola CR, Pezzali I, Bozzini S, Montanaro L, Tanzi MC, Speziale P, Visai L. Antibacterial activity of zinc modified titanium oxide surface. Int J Artif Organs 2006;29:434-442.

27. Campoccia D, Montanaro L, Arciola CR. A review of the biomaterials technologies for infection-resistant surfaces. Biomaterials 2013;34:8533-8554.

28. Arciola CR, Montanaro L, Costerton JW. New trends in diagnosis and control strategies for implant infections. Int J Artif Organs 2011;34:727-736.

29. Bernstein LR. Mechanisms of therapeutic activity for Gallium. Pharmacol Rev 1998;50:665-682.

30. Kaneko Y, Thoendel M, Olakanmi O, Britigan BE, Singh PK. The transition metal gallium disrupts Pseudomonas aeruginosa iron metabolism and has antimicrobial and antibiofilm activity. $\mathrm{J}$ Clin Invest 2007;117:877-888.

31. Kelson AB, Carnevali M, Truong-Le V. Gallium-based anti-infectives: Targeting microbial iron-uptake mechanisms. Curr Opin Pharmacol 2013;13:707-716.

32. Olakanmi O, Britigan BE, Schlesinger LS. Gallium disrupts iron metabolism of mycobacteria residing within human macrophages. Infect Immun 2000;68:5619-5627.

33. Pickup DM, Valappil SP, Moss RM, Twyman HL, Guerry P, Smith ME, Wilson M, Knowles JC, Newport RJ. Preparation, structural characterization and antibacterial properties of Ga-doped sol-gel phosphate-based glass. J Mater Sci 2009;44:1858-1867.

34. Furno F, Morley KS, Wong B, Sharp BL, Arnold PL, Howdle SM, Bayston R, Brown PD, Winship PD, Reid HJ. Silver nanoparticles 
and polymeric medical devices: A new approach to prevention of infection? J Antimicrob Chemother 2004;54:1019-1024.

35. Taglietti A, Arciola CR, D'Agostino A, Dacarro G, Montanaro L, Campoccia D, Cucca L, Vercellino M, Poggi A, Pallavicini P, Visai L. Antibiofilm activity of a monolayer of silver nanoparticles anchored to an amino-silanized glass surface. Biomaterials 2014;35: 1779-1788.

36. Gristina AG, Naylor $P$, Myrvik $Q$. Infections from biomaterials and implants: A race for the surface. Med Prog Technol 1988-1989;14: 205-224.

37. Busscher HJ, van der Mei HC, Subbiahdoss G, Jutte PC, van den Dungen JJ, Zaat SA, Schultz MJ, Grainger DW. Biomaterial-associated infection: Locating the finish line in the race for the surface. Sci Transl Med 2012;4:153rv10.

38. Della Valle C, Visai L, Santin M, Cigada A, Candiani G, Pezzoli D, Arciola CR, Imbriani M, Chiesa R. A novel antibacterial modification treatment of titanium capable to improve osseointegration. Int J Artif Organs 2012;35:864-875.

39. Della Valle C, Rondelli G, Cigada A, Bianchi AE, Chiesa R. A nove silicon-based electrochemical treatment to improve osteointegration of titanium implants. J Appl Biomater Funct Mater 2013;11: 106-116.

40. Le VQ, Cochis A, Rimondini L, Pourroy G, Stanic V, Palkowski H, Carrado A. Biomimetic calcium-phosphates produced by an autocatalytic route on stainless steel $316 \mathrm{~L}$ and bio-inert polyolefin. RSC Adv 2013;3:11255-11262.

41. Fischman SL. Current status of indices of plaque. J Clin Periodontol 1986;13:371-374, 379-380.

42. Johnston L, Vieira AR. Caries experience and overall health status. Oral Health Prev Dent 2014. doi: 10.3290/j.ohpd.a31670.

43. Hofmann CM, Bednar KJ, Anderson JM, Marchant RE. Disruption of Staphylococcus epidermidis biofilm formation using a targeted cationic peptide. J Biomed Mater Res A 2012;100:1061-1067.

44. Cochis A, Fracchia L, Martinotti MG, Rimondini L. Biosurfactants prevent in vitro Candida albicans biofilm formation on resins and silicon materials for prosthetic devices. Oral Surg Oral Med Oral Pathol Oral Radiol 2012;113:755-761.

45. Esposito M, Hirsch JM, Lekholm U, Thomsen P. Biological factors contributing to failures of osseointegrated implants (I). Success criteria and epidemiology. Eur J Oral Sci 1998;106:527-551.

46. Calvert KL, Desai T, Webster TJ. Advances in calcium phosphate coatings-anodic spark deposition: A review. Front Biosci (Landmark Ed) 2014;19:475-489.

47. Campoccia D, Montanaro L, Speziale P, Arciola CR. Antibioticloaded biomaterials and the risks for the spread of antibiotic resistance following their prophylactic and therapeutic clinical use. Biomaterials 2010;31:6363-6377.

48. Giavaresi G, Fini M, Cigada A, Chiesa R, Rondelli G, Rimondini L, Aldini NN, Martini L, Giardino R. Histomorphometric and microhardness assessments of sheep cortical bone surrounding titanium implants with different surface treatments. J Biomed Mater Res A 2003;67:112-120.

49. Giavaresi G, Fini M, Cigada A, Chiesa R, Rondelli G, Rimondini L, Torricelli P, Aldini NN, Giardino R. Mechanical and histomorphometric evaluations of titanium implants with different surface treatments inserted in sheep cortical bone. Biomaterials 2003:24: 1583-1594.
50. Sawase $T$, Jimbo $R$, Wennerberg A, Suketa N, Tanaka $Y$, Atsuta M. A novel characteristic of porous titanium oxide implants. Clin Oral Implants Res 2007;18:680-685.

51. Conserva E, Lanuti A, Menini M. Cell behavior related to implant surfaces with different microstructure and chemical composition: An in vitro analysis. Int J Oral Maxillofac Implants 2010;25:10991107.

52. Singh RG. Evaluation of the bioactivity of titanium after varied surface treatments using human osteosarcoma osteoblast cells: An in vitro study. Int J Oral Maxillofac Implants 2011;26:998-1003.

53. Shim IK, Chung HJ, Jung MR, Nam SY, Lee SY, Lee H, Heo SJ, Lee SJ. Biofunctional porous anodized titanium implants for enhanced bone regeneration. J Biomed Mater Res A 2013. doi: 10.1002/jbm.a.35026.

54. Braem A, Van Mellaert L, Mattheys T, Hofmans D, De Waelheyns E, Geris L, Anné J, Schrooten J, Vleugels J. Staphylococcal biofilm growth on smooth and porous titanium coatings for biomedical applications. J Biomed Mater Res A 2014;102A:215-224.

55. Campoccia D, Arciola CR, Cervellati M, Maltarello MC, Montanaro L. In vitro behaviour of bone marrow-derived mesenchymal cells cultured on fluorohydroxyapatite-coated substrata with different roughness. Biomaterials 2003;24:587-596.

56. Arciola CR, Montanaro L, Moroni A, Giordano M, Pizzoferrato A, Donati ME. Hydroxyapatite-coated orthopaedic screws as infection resistant materials: In vitro study. Biomaterials 1999;20:323327.

57. Baltriukiene D, Sabaliauskas $V$, Balciunas $E$, Melninkaitis A Liutkevicius E, Bukelskiene V, Rutkunas V. The effect of lasertreated titanium surface on human gingival fibroblast behavior. $J$ Biomed Mater Res A 2014;102A:713-720.

58. Dewhirst FE, Chen T, Izard J, Paster BJ, Tanner AC, Yu WH, Lakshmanan A, Wade WG. The human oral microbiome. J Bacteriol 2010;192:5002-5017.

59. Montanaro L, Campoccia D, Rizzi S, Donati ME, Breschi L, Prati C, Arciola CR. Evaluation of bacterial adhesion of Streptococcus mutans on dental restorative materials. Biomaterials 2004;25: 4457-4463.

60. Oettinger-Barak O, Dashper SG, Catmull DV, Adams GG, Sela MN, Machtei EE, Reynolds EC. Antibiotic susceptibility of Aggregatibacter actinomycetemcomitans JP2 in a biofilm. J Oral Microbiol 2013;5.

61. Wang Z, Shen Y, Haapasalo M. Dental materials with antibiofilm properties. Dent Mater 2014;30:e1-e16.

62. Valappil SP, Yiu HH, Bouffier L, Hope CK, Evans G, Claridge JB, Higham SM, Rosseinsky MJ. Effect of novel antibacterial galliumcarboxymethyl cellulose on Pseudomonas aeruginosa. Dalton Trans 2013;42:1778-1786.

63. Babu JP, Garcia-Godoy F. In vitro comparison of commercial oral rinses on bacterial adhesion and their detachment from biofilm formed on hydroxyapatite disks. Oral Health Prev Dent 2014.

64. Coraça-Huber DC, Ammann CG, Fille M, Hausdorfer J, Nogler M, Nagl M. Bactericidal activity of $N$-chlorotaurine against biofilmforming bacteria grown on metal disks. Antimicrob Agents Chemother 2014;58:2235-2239.

65. ISO 3950:2009 Dentistry-Designation system for teeth and areas of the oral cavity, published $05 / 01 / 2009$ by International Organization for Standardization. 